\title{
Current Pharmacological Approaches to Reduce Chorea in Huntington's Disease
}

\author{
Emma M. Coppen ${ }^{1} \cdot$ Raymund A. C. $\operatorname{Roos}^{1}$
}

Published online: 17 December 2016

(c) The Author(s) 2016. This article is published with open access at Springerlink.com

\begin{abstract}
There are currently no effective pharmacological agents available to stop or prevent the progression of Huntington's disease (HD), a rare hereditary neurodegenerative disorder. In addition to psychiatric symptoms and cognitive impairments, HD causes progressive motor disturbances, in particular choreiform movements, which are characterized by unwanted contractions of the facial muscles, trunk and extremities. Management of choreiform movements is usually advised if chorea interferes with daily functioning, causes social isolation, gait instability, falls, or physical injury. Although drugs to reduce chorea are available, only few randomized controlled studies have assessed the efficacy of these drugs, resulting in a high variety of prescribed drugs in clinical practice. The current pharmacological treatment options to reduce chorea in HD are outlined in this review, including the latest results on deutetrabenazine, a newly developed pharmacological agent similar to tetrabenazine, but with suggested less peak dose side effects. A review of the existing literature was conducted using the PubMed, Cochrane and Medline databases. In conclusion, mainly tetrabenazine, tiapride (in European countries), olanzapine, and risperidone are the preferred first choice drugs to reduce chorea among HD experts. In the existing literature, these drugs also show a beneficial effect on motor symptom severity and improvement of psychiatric symptoms. Generally, it is recommended to start with a low dose and increase the dose with close monitoring of any adverse effects. New interesting agents, such as deutetrabenazine and
\end{abstract}

Raymund A. C. Roos

r.a.c.roos@lumc.nl

1 Department of Neurology, Leiden University Medical Center, Albinusdreef 2, 2333 ZA Leiden, The Netherlands pridopidine, are currently under development and more randomized controlled trials are warranted to assess the efficacy on chorea severity in HD.

\section{Key Points}

Tetrabenazine is the only drug approved by the US FDA for the treatment of chorea in Huntington's disease (HD). Monitoring for adverse effects such as depressive symptoms and suicidal behavior is warranted, especially in patients with a history of depression.

In addition to a beneficial effect on chorea, olanzapine, risperidone, and tiapride also seem to have a positive effect on sleep dysfunction, mood disturbances, and the prevention of weight loss.

Potential dopamine-stabilizing and -depleting drugs to reduce motor symptoms in HD are currently under investigation in large multicenter clinical trials.

\section{Introduction}

Huntington's disease (HD) is an inherited autosomal dominant progressive neurodegenerative disorder, with an estimated prevalence of 5-10 per 100,000 in the Caucasian population [1, 2].

The disease is clinically characterized by motor disturbances, cognitive decline, and psychiatric symptoms. One of the most recognized motor signs in HD is chorea, which is characterized by unwanted muscle contractions that are 
progressive over time and interfere in activities of daily living [3].

$\mathrm{HD}$ is caused by a cytosine-adenine-guanine (CAG) trinucleotide repeat expansion in the huntingtin protein located on chromosome 4p16.3 [4]. The mutant huntingtin accumulates within brain cells, causing cell toxicity and dysfunction of neurons throughout the brain when the disease progresses. Neuropathological alterations are found widely throughout the brain, but the primary focus of atrophy is located in the striatum and cerebral cortex $[5,6]$. The distinct striatal atrophy is caused by extensive loss of striatal medium-sized spiny neurons that is suggested to result in the choreiform movements seen in $\operatorname{HD}[7,8]$.

Effective pharmacological treatment to stop the pathophysiological process underlying HD is unfortunately not available. Pharmacological treatment is therefore focused on improving daily functioning by reducing symptom severity $[9,10]$.

Although many potential effective pharmacological options for the treatment of chorea are available, only few randomized controlled studies have been performed that assess the effects on symptom reduction. To date, practicebased studies showed that among HD experts, there is a wide variety in preferred drugs to treat chorea $[10,11]$. Non-pharmacological treatment approaches to reduce chorea are currently also under investigation. For example, pallidal deep brain stimulation (DBS) has been shown to be a safe treatment option [12]. The effects of DBS on motor symptoms are currently under examination in a larger follow-up study.

A review of the existing literature about the pharmacological treatment of chorea in HD was conducted using the PubMed, Cochrane and Medline databases. All literature published before September 2016 was critically reviewed. This review describes the different treatment options that are currently available to reduce chorea in patients with HD.

Also, we will give an outline of current clinical trials involving the latest experimental pharmacological approaches. An overview of the reviewed literature and their most relevant findings is provided in Table 1.

\section{Huntington's Disease (HD)}

\subsection{Clinical Features}

Huntington's disease is characterized by increasingly severe motor disturbances, cognitive impairment, and psychiatric symptoms $[1,13]$. The mean age of disease onset is between 30 and 50 years (ranging from 2 to 85 years), with the mean duration of the disease between 17 to 20 years [1]. The disease can also occur in early childhood (juvenile
HD) or later in life [14]. The clinical onset of HD is still determined by the manifestation of typical motor disturbances, although psychiatric or cognitive dysfunction can be present many years before the onset of motor signs [15]. Cognitive impairment may involve problems with working memory, executive dysfunction, and attention deficits, which progress gradually [16]. Behavioral and psychiatric symptoms in HD include apathy, depression, irritability and aggression, and obsessive-compulsive behavior [13].

The presence and severity of motor disturbances can vary individually but can be divided into involuntary movements such as chorea, dystonia, and tics, and impairments in voluntary movements such as hypokinesia, apraxia, and motor impersistence. Chorea is defined as unwanted, rapid, irregular movements of the extremities and facial jerking, and is usually present in the early stage of the disease [17]. The severity of choreiform movements can vary from very subtle twitches involving the eyebrows or upper face to severe, generalized contractions involving the trunk and limbs that can flow from one extremity to another randomly [3]. Chorea may also interfere with speech, swallowing, gait, and balance [3]. Furthermore, the intensity of the choreiform movements can be influenced by emotions and other stress factors, such as fatigue and anxiety [3].

Dystonia is more often seen in more progressed disease stages and is characterized by sustained or intermittent muscle contractions leading to abnormal posture of the trunk and extremities $[1,18]$.

The degree of motor impairment is commonly assessed with the Unified Huntington's Disease Rating Scale-Total Motor Scale (UHDRS-TMS), a clinical tool that quantifies the severity of motor impairment, with scores ranging from 0 to 124 , with higher scores indicating more severe motor impairment [19]. Here, chorea severity is scored for seven different body areas on a scale from 0 to 4 (with a maximum total chorea score of 28).

\subsection{Chorea and Quality of Life}

Patients with HD are not always aware of the severity of the choreiform movements. However, the progressive nature of motor symptoms in HD impacts daily functioning and interferes with social activities [20]. In later disease stages, the severity of chorea is an independent predictor of fall frequency and gait disturbance [21] and is often the reason for nursing-home placement [22]. Studies investigating the health-related quality of life showed that gait impairments, bradykinesia, and choreiform movements are major contributors to an impaired quality of life for both patients with HD and their caregivers [23, 24].

Specialists start symptomatic treatment in HD in consultation with the patient and family when chorea is 
causing balance disturbances, falls, and physical injury, and when it interferes with daily functioning at work and at home $[3,10]$. In a Europe-wide assessment of medication use among HD patients, $39.3 \%$ of all registered HD patients received medication for the treatment of chorea, comprising dopamine depleting drugs, antipsychotics, or antiparkinsonian medication [25].

\subsection{Neurotransmission in HD}

In the normal human brain, the striatum comprises up to 95\% of medium spiny neurons. These projection neurons are involved in the feedback loop that suppresses involuntary movements. In HD, atrophy of the striatum is the pathological hallmark of the disease and the medium spiny neurons are the most affected cells [7, 26]. Loss of medium spiny neurons causes abnormal neurotransmission of the dopamine, glutamate, and gamma-amino butyric acid (GABA) systems and is therefore the main focus of pharmacotherapy in HD [9].

Dopamine is a major neurotransmitter that is involved in movement control, cognition, motivation, reward processing, and emotion modulation [27, 28]. Specific dopamine receptors are widely expressed throughout the central nervous system and are activated by dopamine on pre- and post-synaptic neurons. Free, unbound dopamine can be transported to the pre-synaptic terminal via the highaffinity dopamine transporter (DAT). Here, it is re-packaged into vesicles by the vesicular monoamine transporter type 2 (VMAT2) or broken down into inactive metabolites by enzymes such as monoamine oxidase [28].

The neurodegenerative processes in HD cause mainly postsynaptic dopaminergic dysfunction of dopaminergic type $1\left(D_{1}\right)$ and type $2\left(D_{2}\right)$ receptors in the striatum [28-30].

Dopaminergic dysfunction is found in both premanifest and manifest HD, where manifest patients show a greater loss of striatal $\mathrm{D}_{1}$ and $\mathrm{D}_{2}$ receptor binding [31, 32].

In PET studies, this decrease in dopamine receptor binding seems to be correlated with clinical motor assessment (UHDRS-TMS), functional capacity scores, and assessments that measure executive dysfunction [33].

As it is hypothesized that choreiform movements in HD are related to overstimulation of dopamine receptors, pharmacological agents that modify the activity of the dopaminergic system have been of specific interest. Still, the glutamate neurotransmitter system is already affected in early disease stages and it is suggested that increased glutamatergic neurotransmission in the thalamocortical pathways also contributes to hyperkinetic movements [7].

Further, it is proposed that modulation of peripheral manifestations of the disease, such as signs of the muscular, circulatory, metabolic, and digestive systems, might offer new approaches to therapeutic development and can have an additional positive effect on motor symptoms [34].

In the following paragraphs, we discuss the available drugs for treating chorea in patients with HD classified by neurotransmitter affinity.

\section{Pharmacological Treatment of Chorea in HD}

\subsection{Tetrabenazine}

Tetrabenazine was synthesized in 1956 and first introduced in the 1970s for the management of hyperkinetic movement disorders [35]. Tetrabenazine is a reversible dopamine-depleting drug that selectively binds to the central VMAT2 and depletes monoamines by inhibiting their transport into presynaptic vesicles [36, 37].

Tetrabenazine is rapidly metabolized into two metabolites, alpha- and beta-dihydrotetrabenazine via CYP2D6, a hepatic isoenzyme, with maximum concentrations reached in $1.5 \mathrm{~h}$ after dosing [38]. Elimination of tetrabenazine and its metabolites is primarily renal. As the half-life of the metabolites is between 2 and $8 \mathrm{~h}$ [38, 39], tetrabenazine should be administered two to three times daily.

The TETRA-HD study, the first randomized controlled dose-finding study of tetrabenazine conducted by the Huntington Study Group (HSG), demonstrated the efficacy of tetrabenazine in HD [39]. This study was essential for the US Federal Drug Administration (FDA) approval of tetrabenazine as a treatment for chorea. Since 2008, tetrabenazine is the only drug that the FDA has approved for the treatment of chorea in HD and is also available in Canada, Australia, New Zealand, and Western Europe.

In the TETRA-HD study, participants with HD received tetrabenazine $(n=54)$ or placebo $(n=30)$ for 12 weeks [39]. Tetrabenazine was titrated weekly in $12.5 \mathrm{mg}$ increments up to a maximum dosage of $100 \mathrm{mg}$ per day. After 12 weeks of treatment, there was a significant reduction of chorea severity by 5.0 units on the UHDRS total chorea score (SD 0.5, $p<0.0001$ ) in the tetrabenazine group compared with a reduction of 1.5 units (SD 0.7) in the placebo group. Overall, this represents an average reduction in chorea severity of $23.5 \%$ due to tetrabenazine. There was, however, no improvement on the total motor score of the UHDRS.

To assess the long-term safety and efficacy of tetrabenazine in the treatment of chorea in HD, participants who completed the TETRA-HD study were invited to participate in the open-label extension study for up to 80 weeks [40]. In this study, participants were titrated to the best individual dose with a maximum of $200 \mathrm{mg}$ per day, with a mean dosage at week 80 of $63.4 \mathrm{mg}$ (range $12.5-175 \mathrm{mg}$ ). In total, 45 of the 75 initially enrolled 


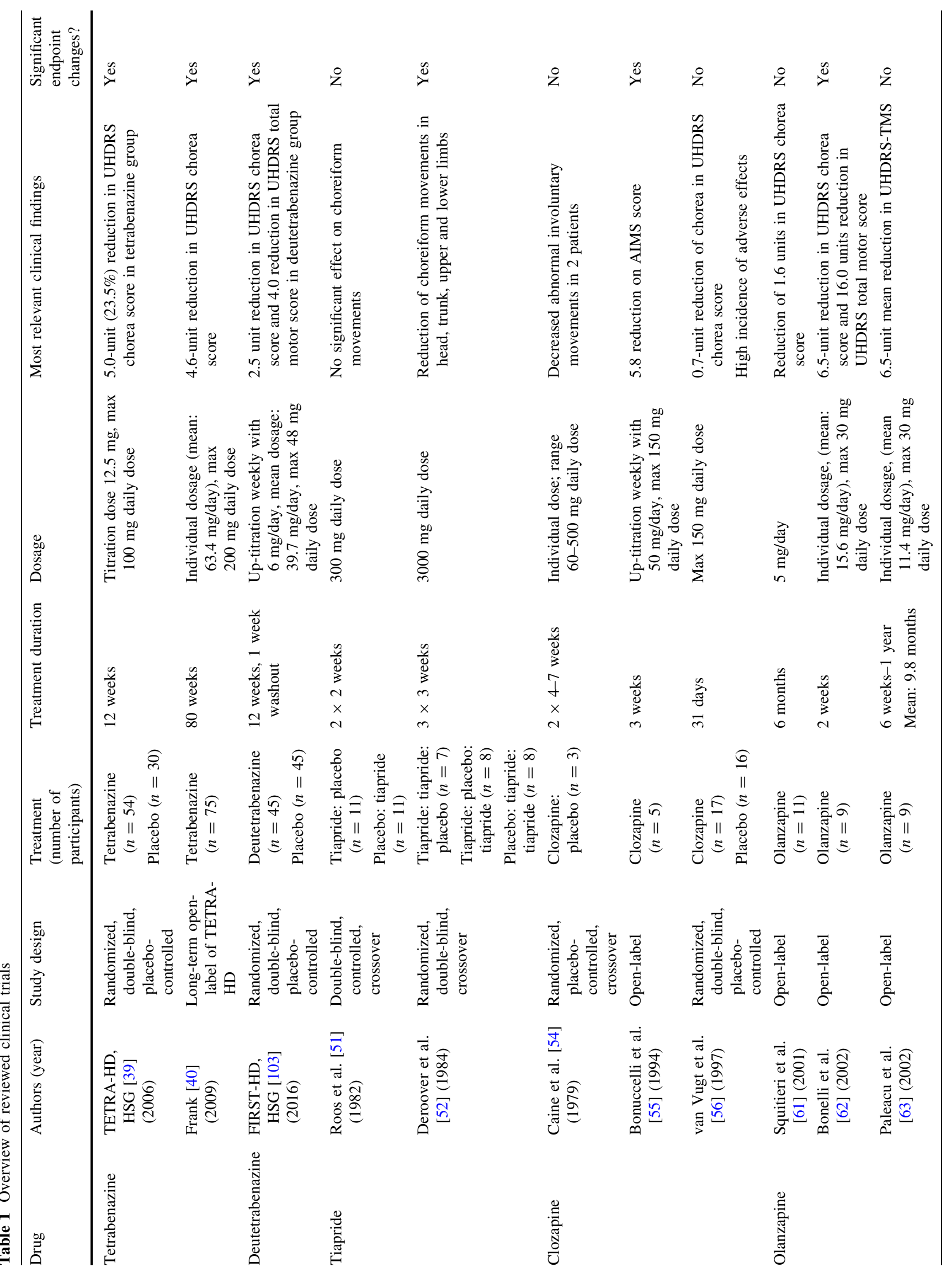




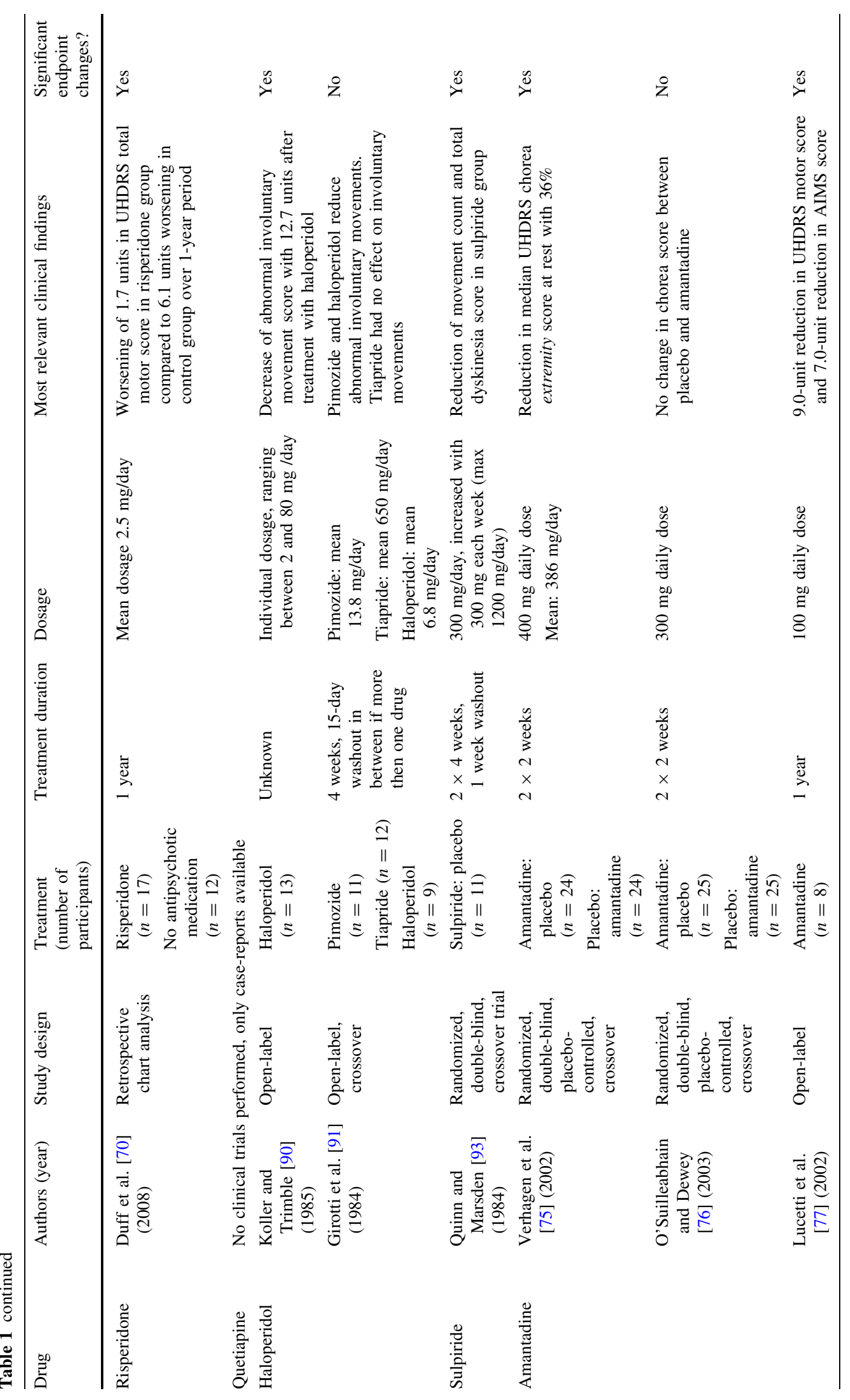




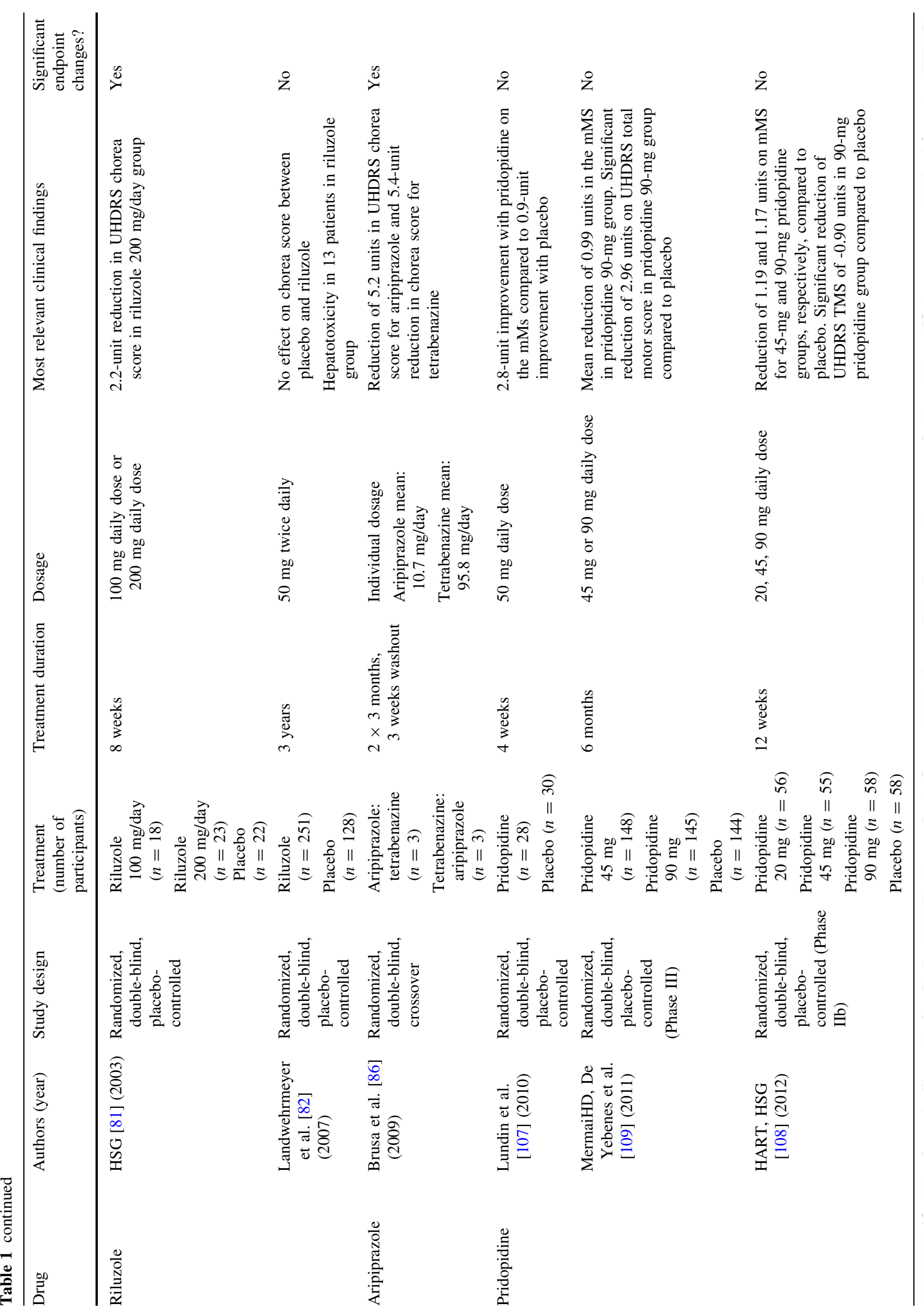

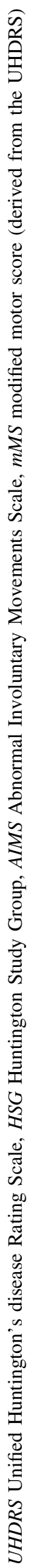


participants completed the 80 -week trial. After 80 weeks of treatment, there was a significant reduction of mean UHDRS total chorea score of 4.6 units (SD 5.5, $p<0.001$ ). After a washout period of 1 week, participants on tetrabenazine showed an increase in chorea severity, demonstrating a symptomatic advantage of tetrabenazine [39, 40].

The effectiveness of tetrabenazine for the treatment of chorea was additionally confirmed by several other small observational and open-label studies [41-44].

However, besides the overall symptomatic advantage of tetrabenazine in reducing chorea in these clinical trials, many adverse effects have been reported, thus limiting its clinical benefit. The most commonly reported adverse effects include sedation, fatigue, depression, anxiety, akathisia, agitation, dysphagia, nausea, parkinsonism, and dystonia [39-44] (Table 2).

Some adverse effects seem to be related to peak concentrations of active circulating metabolites and can be managed by dose reduction. Nevertheless, depression and suicidal behavior can be exacerbated by tetrabenazine, especially in patients with a history of depressive mood. Tetrabenazine is therefore contraindicated in patients who are actively suicidal and in patients with inadequately treated depression [35]. Furthermore, concomitant treatment with antidepressant drugs that have strong CYP2D6inhibiting effects (such as fluoxetine and paroxetine) can lead to increased levels of the active metabolite due to a prolonged half-life. In case of concomitant use of CYP2D6 inhibitors, a $50 \%$ reduction of the daily tetrabenazine dose is recommended [10].

A Cochrane review examined 22 studies with various pharmacological interventions for the symptomatic treatment of HD that were published up to December 2007 [2]. The authors of the Cochrane review conclude that only tetrabenazine showed a clear effect in reducing chorea in HD based on the results of the TETRA-HD study.

In clinical practice, many specialists prefer tetrabenazine as a first choice therapy if there are no signs of depressive symptoms or suicidal behavior [25, 45].

Combining these results, tetrabenazine seems generally safe and well tolerated, with dose-dependent adverse effects. It is recommended to prescribe tetrabenazine in the absence of severe depression and psychosis [46]. Tetrabenazine must be started at a low dosage (12.5-25 mg per day) and titrated with small increments to a therapeutic dosage of $50-75 \mathrm{mg}$ per day (the maximum dosage is 100-200 mg/day), with monitoring after each titration. Frequent dosing is required due to the short half-life of the active metabolites. It is therefore suggested that the total daily dosage of tetrabenazine should be divided over two to four doses per day. It can also be helpful to administer the main dosage at night, because of the potentially sedative adverse effects. In addition, patients must be closely monitored for the development of depressive symptoms or suicidal ideation.

\subsection{Dopamine Antagonists}

It is suggested that the effect of dopamine antagonists in the treatment of chorea is caused by blocking postsynaptic dopamine $\mathrm{D}_{2}$ receptors leading to the suppression of chorea [47]. Another hypothesis is that the observed symptomatic effect is due to nonspecific or sedating effects [48].

Besides the potential positive effects on choreatic symptoms, dopamine antagonists are known to cause adverse effects due to dopamine $\mathrm{D}_{2}$ receptor blockage. Adverse effects include dyskinesias, rigidity, cognitive impairment, hypotension, and sedative effects.

In 2012, the American Academy of Neurology (AAN) presented an evidence-based guideline for the pharmacological treatment of chorea [49]. The authors conclude that there was insufficient data available to make recommendations regarding the use of dopamine antagonists, as evidence of the efficacy of dopamine antagonists on chorea is based on small clinical trials and case reports. However, according to an international group of HD experts, antipsychotic drugs were a first-choice treatment option in most North American and European countries, especially when psychiatric symptoms such as psychosis, depression, or aggressive behavior were present [10].

Typical first-generation antipsychotic drugs are currently less popular in clinical practice because of the risk of extrapyramidal adverse effects, such as tardive dyskinesia and because of their sedative effects. Modern secondgeneration atypical antipsychotic drugs (such as risperidone, olanzapine, and quetiapine) are mainly preferred by clinicians, as these drugs generally provide better tolerability than first-generation antipsychotics [10]. Here, we discuss the most commonly prescribed and studied dopamine antagonists for the treatment of chorea in HD. Table 2 presents a summary of the most frequently prescribed drugs to treat chorea in HD including commonly reported adverse effects, contraindications, and drug interactions.

\subsubsection{Tiapride}

Tiapride is a first-generation $\mathrm{D}_{2}$ receptor antagonist that is only available in European countries. Although tiapride is a classic antipsychotic drug, it is a frequent choice for the treatment of chorea by HD experts [10, 11]. In a survey among international HD experts, $50 \%$ of the European respondents regarded tiapride as the first choice for treating treat chorea [10].

Tiapride has an oral bioavailability of about $75 \%$, with peak plasma concentrations reached in $1 \mathrm{~h}$ after oral 
administration, a half-life of $2.6-4 \mathrm{~h}$, and is eliminated mostly by urinary excretion [50].

Only two small randomized, controlled studies have been performed to assess the efficacy of tiapride on choreatic symptoms [51, 52]. Little interest from the pharmaceutical industry to evaluate the efficacy of tiapride on chorea might be an explanation for the lack of adequate studies having been performed.

A double-blind, controlled, crossover study investigated the effect of tiapride in $22 \mathrm{HD}$ patients [51]. Choreatic symptoms were assessed using video recordings at several time points. Although individuals subjectively responded well to the tiapride treatment, the authors did not find a significant reduction of choreiform movements after treatment with $300 \mathrm{mg}$ tiapride per day for 2 weeks.

Another randomized double-blind study with 29 HD patients examined the effect of tiapride with placebo using a crossover design of two 3-week periods of tiapride alternated with a single 3 -week placebo period [52]. Six patients did not finish the different treatment periods, two of whom because of drug-related adverse effects. Patients were administered $1200 \mathrm{mg}$ tiapride in the morning, $900 \mathrm{mg}$ in the afternoon, and another $900 \mathrm{mg}$ in the evening. Choreiform movement of the face, neck, trunk, and extremities were assessed on a 4-point severity scale. After treatment with tiapride, patients showed a significant reduction of choreiform movements in four out of five body regions (head, $p=0.00$; trunk, $p=0.05$; upper limbs, $p=0.01$; lower limbs, $p=0.01$ ). However, these results should be interpreted with caution, as no wash-out period between tiapride and placebo periods was performed, which is preferred with crossover study designs. Reported adverse effects include sedative effects such as drowsiness and extrapyramidal signs $[51,52]$.

Although the existing evidence does not show a favorable effect of tiapride on chorea, tiapride is widely used by European clinicians in daily practice [25].

\subsubsection{Clozapine}

Clozapine is an atypical neuroleptic drug commonly used in the treatment of schizophrenia [53]. Since clozapine has a low incidence of extrapyramidal side effects, it is also suggested to be a suitable symptomatic drug for chorea.

Clozapine has a relatively high affinity for dopamine $\mathrm{D}_{1}$ and $\mathrm{D}_{4}$ receptors and relatively low $\mathrm{D}_{2}$ dopaminergic antagonistic properties in contrast to typical neuroleptic drugs [53]. Orally, clozapine is rapidly absorbed and reaches peak plasma concentration in approximately $3 \mathrm{~h}$ [53]. Clozapine is eliminated by hepatic cytochrome isoenzymes with an elimination half-life of $14 \mathrm{~h}$. Sertraline, paroxetine, and fluoxetine have been reported to increase plasma concentrations of clozapine, whereas coadministration with carbamazepine or rifampin reduced clozapine plasma concentrations [53].

Two small studies ( $n=3$ and $n=5$, respectively) reported clear reductions in abnormal involuntary movements in patients with $\mathrm{HD}$ at different dosages between 50 and $500 \mathrm{mg}$ per day [54, 55]. However, a randomized double-blind trial conducted in 33 patients with HD reported only a small beneficial effect of clozapine in the reduction of chorea [56]. In this study, patients received clozapine up to a maximum dosage of $150 \mathrm{mg}$ clozapine $(n=17)$ or placebo $(n=16)$ per day for a period of 31 days. A small reduction of chorea (0.7 units) on the UHDRS total chorea score was seen, but this was not significant $(p=0.81)$. Conversely, there were significant adverse events reported, including fatigue, dizziness, walking difficulties, and hypersalivation. Overall, eight patients needed a reduction of clozapine dosage and another six patients were unable to complete the trial because of adverse reactions. Therefore, the authors do not advise the use of clozapine for the treatment of chorea. In clinical practice studies, clozapine is not prescribed to treat chorea in HD [10, 25].

\subsubsection{Olanzapine}

In the UK, olanzapine is the most commonly prescribed dopamine antagonist for the treatment of motor and behavioral symptoms in HD [11]. Olanzapine is an atypical antipsychotic drug with a broad pharmacokinetic profile with high affinity for serotonergic $\left(5 \mathrm{HT}_{2 \mathrm{~A}}, 5 \mathrm{HT}_{2 \mathrm{C}}, 5 \mathrm{HT}_{3}\right)$ receptors, but antagonizes dopamine $\left(\mathrm{D}_{2}\right)$ receptors $[57,58]$. Olanzapine has a oral bioavailability of $60 \%$, as $40 \%$ is inactivated by first-pass hepatic metabolism [58]. Olanzapine reaches a maximum plasma concentration within 5-8 $\mathrm{h}$ and has a mean half-life in healthy individuals of approximately $33 \mathrm{~h}$. Fluvoxamine or estrogens (CYP1A2 inhibitors) have been shown to increase plasma concentrations of olanzapine, whereas carbamazepine, omeprazole, and rifampin (CYP3A4 inducers) may reduce olanzapine plasma concentrations [58, 59].

Several case reports and small open-label studies have been performed to assess the anti-choreiform effect of olanzapine in HD patients [60-63]. In a 6-month openlabel trial of olanzapine, 11 patients with HD received $5 \mathrm{mg}$ olanzapine per day and reported a significant effect on behavioral subscores (depression, anxiety, irritability, and obsessive symptoms) [61]. Although a moderate improvement in chorea score (mean reduction of 1.6 units) was also observed, this effect was not significant.

Following up on this study, a prospective open-label study administered olanzapine in increasing doses (max $30 \mathrm{mg} /$ day, mean dosage of $15.6 \mathrm{mg} /$ day) to nine 
predominantly choreatic HD patients [62]. No adverse events were reported. After 2 weeks of treatment with olanzapine, UHDRS chorea scores improved from 13.4 (SD 6.8) before treatment to 6.9 (SD 5.0) after treatment with olanzapine. The authors state that six patients continued treatment with olanzapine after the study for a period of 3-24 months and all remained at a constant total motor score.

Another study evaluated the effects of olanzapine in nine HD patients [63]. The reason for olanzapine treatment was based on the presence of psychiatric symptoms (e.g., depression, psychosis, disruptive behavior, and agitation) in all participants. The mean olanzapine dose was $11.4 \mathrm{mg} /$ day and mean treatment duration was 9.8 months. A reduction of 6.5 units on the UHDRS total motor score was observed after treatment with olanzapine, but this was not significant.

Overall, olanzapine is safe and well tolerated. In daily practice, olanzapine is mainly preferred due to its positive effects on chorea, weight gain, and sleep dysfunction, and can be recommended specifically when psychiatric symptoms such as irritability are also present $[10,28]$.

\subsubsection{Risperidone}

Risperidone acts as a $5-\mathrm{HT}_{2 \mathrm{~A}}$ and $\mathrm{D}_{2}$ receptor antagonist and is generally used in the treatment of schizophrenia and the acute manic phase of bipolar disorders [64]. Although risperidone is an atypical antipsychotic drug, it behaves more as a typical antipsychotic drug, as there is a relatively high risk of developing tardive dyskinesia and other extrapyramidal effects compared to other second-generation antipsychotics [65]. Risperidone has a good oral bioavailability of $70-85 \%$, with peak plasma concentrations reached in $1 \mathrm{~h}$ and a mean half-life of $22 \mathrm{~h}$ of the active metabolite [58]. As risperidone is metabolized via CYP2D6 in the liver, simultaneous use of CYP2D6 inhibitors (such as fluoxetine and paroxetine) can increase the plasma concentration of risperidone [58, 59].

The use of risperidone for the treatment of chorea in HD is not investigated in clinical trials. Several case-reports on risperidone describe a reduction in motor symptoms and improvement of psychiatric symptoms [66-69].

A retrospective chart analysis study compared $17 \mathrm{HD}$ patients taking risperidone (mean dose of $2.5 \mathrm{mg}$ per day) with $12 \mathrm{HD}$ patients not taking any antipsychotic medication [70]. Here, risperidone had a beneficial effect on psychiatric symptoms associated with HD over a period of 14 months. According to the authors, risperidone also showed a trend toward stabilizing motor decline, as the total motor scores did not change over time.

Among HD experts, risperidone was reported by $43 \%$ of the respondents as the first choice antipsychotic drug for the treatment of chorea [10].
Although evidence about the safety and tolerability of risperidone in patients with HD is lacking, the current clinical reports suggest that risperidone might improve motor symptoms in $\mathrm{HD}$, specifically when psychiatric symptoms are present.

\subsubsection{Quetiapine}

Only three case reports thus far have reported the use of quetiapine in patients with HD [71-73]. Despite the lack of scientific evidence, a survey among an international group of HD experts revealed that $12 \%$ of the respondents prefer quetiapine as a first-choice antipsychotic drug for the treatment of chorea, especially when psychiatric symptoms, such as irritability, are present [10].

Quetiapine is an atypical antipsychotic drug that interacts with several neurotransmitter receptors. It exhibits high affinity for serotonin $\left(5 \mathrm{HT}_{2}\right)$ and dopamine $\mathrm{D}_{2}$ receptors, thus explaining the low incidence of extrapyramidal side effects [58]. Maximum plasma concentrations are reached within $1-1.5 \mathrm{~h}$ and the drug is eliminated through the liver with a mean half-life of approximately $6 \mathrm{~h}$ [58].

Two case-reports suggest that quetiapine is potentially effective for treatment of positive psychotic symptoms in HD [71] and for the treatment of behavioral symptoms such as agitation, irritability, and insomnia [72]. Another case-report of a patient with HD without psychiatric symptoms but with severe choreiform movements revealed an improvement on the UHDRS chorea score after 9 weeks of treatment with $300 \mathrm{mg}$ olanzapine daily [73]. In this patient, fine motor tasks and gait markedly improved, and the patient was able to perform better in daily tasks, without reporting any adverse effects.

Quetiapine seems to be well tolerated; adverse effects of quetiapine observed by HD experts are weight gain, sedation, akathisia, and dry mouth [10]. Possibly due to the lack of scientific reports, quetiapine is not often selected as a first choice to treat chorea $[10,11]$.

To summarize, although there are few evidence-based studies performed regarding the effectiveness of dopamine antagonists as a symptomatic treatment option for reducing chorea, dopamine antagonists seem to have a beneficial effect on chorea in HD. Despite the lack of evidence, it is already common to prescribe dopamine antagonists as a first choice for treating chorea in clinical practice $[10,11]$. In particular, tiapride (in European countries), olanzapine, and risperidone are preferred among HD experts and overall show a beneficial effect on motor symptom severity and improvement of psychiatric symptoms in the existing literature. When prescribing dopamine antagonists for the treatment of chorea, it is suggested to start with a low dose, which can be increased, depending on the presence of 
adverse effects and patients' tolerance. Future large randomized, double-blind, placebo-controlled trials of dopamine antagonists are necessary to determine if these drugs are advantageous for the treatment of chorea.

\subsection{Anti-Glutamatergic Drugs}

\subsubsection{Amantadine}

Amantadine is a noncompetitive $N$-methyl-D-aspartic acid (NMDA) receptor antagonist and is commonly used in the treatment of extrapyramidal symptoms in Parkinson's disease (PD). Amantadine reaches peak plasma concentrations after $1-4 \mathrm{~h}$, is poorly metabolized in humans via renal secretion ( $90 \%$ can be recovered unchanged in urine), and has a relatively short half-life of $12 \mathrm{~h}$ in young adults [74].

Although amantadine is recommended as an alternative for tetrabenazine by the AAN guidelines for the treatment of chorea in HD [49], there is limited evidence about the efficacy and safety of amantadine in patients with HD.

Two small placebo-controlled, randomized trials were performed to assess the effects of oral amantadine on motor and cognitive function in HD. In one study, 24 patients with HD received amantadine (400 mg per day) or placebo in a double-blind, crossover study for 4 weeks [75]. Results from video assessments and live ratings of the chorea score showed a significant reduction of $36 \%$ in the median chorea score of the extremities at rest after treatment with amantadine, compared to placebo. However, the effects of amantadine on chorea and the plasma concentrations varied considerably between patients. Also, the authors did not report absolute differences on chorea scores as results are only given in percentage change. In the second placebocontrolled study, however, there was no significant change in chorea score between placebo and amantadine [76]. In this study, the same randomized crossover design was performed using amantadine $300 \mathrm{mg}$ per day interspersed with placebo for 4 weeks in $25 \mathrm{HD}$ patients.

A small open-label study also reported a significant reduction of dyskinesias on the UHDRS motor score ( -9.0 units) and Abnormal Involuntary Movement Scale (AIMS) score (-7.0 units) in eight HD patients receiving $100 \mathrm{mg}$ amantadine for a 1-year period [77].

Frequent reported adverse effects during amantadine treatment included insomnia, hallucinations and confusion, agitation or anxiety, dry mouth, nausea, and diarrhea [75, 76].

The authors of the Cochrane review combined both randomized, placebo-controlled studies to perform a meta-analysis [2]. These pooled results did not show any significant effect of amantadine for the treatment of chorea. Furthermore, in a survey among HD experts, the use of amantadine to treat chorea was highly debatable and only few experts use amantadine, especially in first- and second-line clinical settings [10]. Based on the above-mentioned results, treatment with amantadine showed various findings but overall does not seem effective in reducing chorea in HD.

\subsubsection{Riluzole}

Riluzole is a glutamate release inhibitor that displays antiexcitotoxic characteristics [78]. Therefore, riluzole is proposed as a potential neuroprotective agent for treatment in HD. Peak plasma concentrations are reached in $14 \mathrm{~h}$, with a bioavailability of $60 \%$. Riluzole is eliminated via urinary excretion for $85-95 \%$ in the first $24 \mathrm{~h}$ after administration [78].

In HD, two small open-label studies showed significant improvements in chorea scores in patients treated with riluzole $100 \mathrm{mg} / \mathrm{day}$ for 6 weeks [79] and $50 \mathrm{mg}$ twice daily for 1 year [80]. The HSG therefore conducted a multicenter, randomized, double-blind study to evaluate the short-term, dosage-related impact of riluzole on chorea in 63 patients with HD [81].

In this study, riluzole $100 \mathrm{mg} /$ day $(n=18)$, riluzole $200 \mathrm{mg} /$ day $(n=23)$, or a placebo $(n=22)$ was given twice daily for 8 weeks [81]. There was a reduction in mean chorea score of 2.2 units (SD 3.3) in the riluzole $200 \mathrm{mg} /$ day group compared to the placebo group. There were no significant differences in chorea scores between riluzole $100 \mathrm{mg}$ /day and placebo.

The total motor score of the UHDRS improved by 4.0 units (SD 7.1) for participants with riluzole $200 \mathrm{mg}$ /day and worsened by 1.6 units (SD 7.4) in the placebo group.

Adverse effects occurring during the study included dizziness, fatigue, muscle weakness, nausea, and somnolence. Most importantly, riluzole caused elevation of hepatic liver enzymes in eight patients in the group of riluzole $100 \mathrm{mg} / \mathrm{day}$, and 14 cases in the riluzole group of $200 \mathrm{mg} /$ day. One participant had associated abdominal pain and increased hepatic liver enzymes that resolved upon discontinuing the drug. The authors conclude that they were unable to confirm the effect of riluzole $100 \mathrm{mg} /$ day reported in the previous open-label studies [79-81].

Additionally, participants in all three pilot studies used concomitant neuroleptic drugs for treatment of chorea, complicating the interpretation of the results.

To evaluate the long-term efficacy in slowing disease progression, a large randomized, double-blind trial of riluzole in HD was performed [82]. In total, 537 patients were randomized to treatment with riluzole $(50 \mathrm{mg}$ twice daily) or placebo. After 3 years, 279 patients completed the study. There was no significant change in chorea score over time observed at any time point during the study.

Moreover, significant increased serum markers that indicate hepatotoxicity were observed in 13 patients in the riluzole group, of whom five patients had to discontinue, 
Table 2 Most frequently prescribed drugs for chorea in Huntington's disease (HD)

\begin{tabular}{|c|c|c|c|}
\hline Drug & Adverse effects & Contraindications & Drug interactions \\
\hline Tetrabenazine & $\begin{array}{l}\text { Depression, somnolence, } \\
\text { parkinsonism, insomnia, } \\
\text { akathisia, anxiety, nausea }\end{array}$ & $\begin{array}{l}\text { Active depression or suicidal ideation, } \\
\text { psychosis, impaired hepatic function, } \\
\text { concomitant use of MAO-inhibitors }\end{array}$ & $\begin{array}{l}\text { Reduce tetrabenazine dose with concomitant use } \\
\text { of fluoxetine and paroxetine }\end{array}$ \\
\hline Olanzapine & $\begin{array}{l}\text { Sedation, weight gain, dry } \\
\text { mouth, Parkinsonism }\end{array}$ & None specific & $\begin{array}{l}\text { Drugs that induce CYP1A2 enzymes } \\
\text { (carbamazepine, omeprazole, rifampin) may } \\
\text { reduce olanzapine plasma levels. CYP1A2 } \\
\text { inhibitors (estrogens, fluvoxamine) may increase } \\
\text { plasma levels }\end{array}$ \\
\hline Risperidone & $\begin{array}{l}\text { Parkinsonism, akathisia, } \\
\text { sedation, } \\
\text { hyperprolactinemia }\end{array}$ & None specific & $\begin{array}{l}\text { Drugs that induce CYP3A4 enzymes } \\
\text { (carbamazepine, phenobarbital, phenytoin) may } \\
\text { reduce risperidone plasma levels. Fluoxetine and } \\
\text { paroxetine can increase plasma concentration }\end{array}$ \\
\hline Tiapride $^{\mathrm{a}}$ & Sedation, parkinsonism & $\begin{array}{l}\text { Prolactin-dependent tumors, history of } \\
\text { QT-prolongation }\end{array}$ & $\begin{array}{l}\text { Concomitant use of levodopa or other dopamine } \\
\text { agonists is contraindicated. Sedative effect of } \\
\text { tiapride can be increased in combination with } \\
\text { antidepressants, benzodiazepines and opioids }\end{array}$ \\
\hline Quetiapine & $\begin{array}{l}\text { Weight gain, dry mouth, } \\
\text { parkinsonism, sedation, } \\
\text { akathisia }\end{array}$ & History of QT-prolongation, neutropenia & $\begin{array}{l}\text { CYP3A4 inhibitors (clarithromycin, erythromycin, } \\
\text { ketoconazole) can increase quetiapine plasma } \\
\text { levels. Increase quetiapine dose with } \\
\text { concomitant use of CYP3A4 enzyme inducers } \\
\text { (carbamazepine, rifampin, phenytoin, } \\
\text { glucocorticoids) }\end{array}$ \\
\hline Aripiprazole & $\begin{array}{l}\text { Sedation, parkinsonism, } \\
\text { akathisia, cardiac } \\
\text { arrhythmias }\end{array}$ & None specific & $\begin{array}{l}\text { CYP2A4 or CYP2D6 inhibitors (ketoconazole, } \\
\text { quinidine, fluoxetine, paroxetine) can inhibit } \\
\text { aripiprazole elimination and cause increased } \\
\text { blood levels. Concomitant use of serotonergic } \\
\text { drugs can increase risk of serotonergic syndrome }\end{array}$ \\
\hline Clozapine & $\begin{array}{l}\text { Orthostatic hypotension, } \\
\text { sedation, weight gain, } \\
\text { increased seizure risk, } \\
\text { agranulocytosis }\end{array}$ & $\begin{array}{l}\text { Myeloproliferative disorders, history of } \\
\text { agranulocytosis, uncontrolled epilepsy, } \\
\text { paralytic ileus, or hepatic dysfunction }\end{array}$ & $\begin{array}{l}\text { Reduce dose when combining with fluvoxamine } \\
\text { and paroxetine. Drugs that induce cytochrome } \\
\text { P450 enzymes may decrease clozapine plasma } \\
\text { levels }\end{array}$ \\
\hline Haloperidol & $\begin{array}{l}\text { Tardive dyskinesia, sedation, } \\
\text { parkinsonism, akathisia, } \\
\text { tachycardia }\end{array}$ & $\begin{array}{l}\text { Coma, history of QT prolongation or } \\
\text { other clinical significant cardiac } \\
\text { diseases }\end{array}$ & $\begin{array}{l}\text { CYP3A4 or CYP2D6 isoenzymes inhibitors } \\
\text { (venlafaxine, fluvoxamine, sertraline, buspirone, } \\
\text { and alprazolam) } \\
\text { Rifampin or carbamazepine can reduce } \\
\text { haloperidol plasma levels. }\end{array}$ \\
\hline Sulpiride & $\begin{array}{l}\text { Sedation, parkinsonism, } \\
\text { hyperprolactinemia, } \\
\text { akathisia, weight gain }\end{array}$ & $\begin{array}{l}\text { Pheochromocytoma, prolactin-dependent } \\
\text { tumors (such as pituitary tumors, breast } \\
\text { cancer) }\end{array}$ & $\begin{array}{l}\text { Concomitant use of levodopa or other dopamine } \\
\text { agonists is contraindicated }\end{array}$ \\
\hline Amantadine & $\begin{array}{l}\text { Insomnia, hallucinations, } \\
\text { anxiety, agitation, cardiac } \\
\text { arrhythmias, dry mouth }\end{array}$ & $\begin{array}{l}\text { Refractory epilepsy, psychosis, acute } \\
\text { glaucoma }\end{array}$ & $\begin{array}{l}\text { Adverse effects of anticholinergic drugs may be } \\
\text { increased with concomitant use of amantadine. } \\
\text { Quinine can reduce the renal clearance of } \\
\text { amantadine }\end{array}$ \\
\hline
\end{tabular}

Drugs listed in this table are the most commonly prescribed drugs for the treatment of chorea based on international surveys among HD experts and registered HD patients (Priller et al. [11], Orth et al. [25], Burgunder et al. [10]). Most commonly reported adverse effects, contraindications, and drug interactions are described (Brown et al. [64], Videnovic [59])

a Tiapride is only available in European countries

compared to one patient in the placebo group. The increased incidence of elevated liver enzymes in patients treated with riluzole is consistent in studies with riluzole performed in patients with ALS [83].

Although the AAN guidelines suggest clinicians prescribe riluzole ( $200 \mathrm{mg} /$ day) to treat chorea, long-term evaluation and large cohort studies showed no beneficial effect to support this recommendation, and the AAN recommendations were discussed critically by HD experts [46]. Furthermore, riluzole is not prescribed by HD experts in clinical practice [10].

\subsection{Aripiprazole}

Aripiprazole is a second-generation antipsychotic drug, generally prescribed in schizophrenia and schizoaffective 
disorders. Common atypical antipsychotics are $\mathrm{D}_{2}$ receptor antagonists, but aripiprazole acts as a partial agonist on dopaminergic $\mathrm{D}_{2}$ and serotoninergic $5-\mathrm{HT}_{1 \mathrm{~A}}$ receptors and as an antagonist on the serotoninergic $5-\mathrm{HT}_{2 \mathrm{~A}}$ receptors [84]. Therefore, aripiprazole is well tolerated and rarely causes extrapyramidal and metabolic adverse effects in schizophrenia [84]. Aripiprazole is well absorbed, with peak plasma concentrations occurring within 3-5 h of administration and with an oral availability of $87 \%$ [58]. The mean elimination half-life is about $75 \mathrm{~h}$ and occurs through hepatic metabolism via two P450 isozymes, CYP3A4 and CYP2D6 [58].

In $\mathrm{HD}$, no randomized, controlled trials have been performed to investigate the effect of aripiprazole on choreiform movements. Nevertheless, $11 \%$ of an international group of HD experts prescribe aripiprazole for the treatment of chorea [10].

A case report has described a beneficial effect of aripiprazole on choreiform movements in three advanced HD patients [85]. Besides the presence of severe dyskinesias, behavioral changes and mood disturbances were also reported. Aripiprazole was well tolerated and a reduction of choreiform movements was seen on the UHDRS total motor score in all patients, and this remained stable over a 12-month follow-up period.

Another small crossover study compared the effects of aripiprazole with tetrabenazine in six patients with HD [86]. All patients received aripiprazole twice daily (mean daily dose $10.7 \mathrm{mg}$ ) and tetrabenazine twice daily (mean daily dose $95.8 \mathrm{mg}$ ) in random order for 3 months, with a washout period of 3 weeks between the two drugs. Treatment with aripiprazole showed a reduction of 5.2 units in the UHDRS chorea score, whereas tetrabenazine treatment caused a reduction of 5.4 units in the UHDRS chorea score. HD patients treated with aripiprazole reported a better tolerability with less sedation, depressive mood, and sleepiness then when treated with tetrabenazine [86]. However, another study reports that the use of aripiprazole in psychiatric disorders is associated with tardive dyskinesia [87]. To make a fair comparison between the efficacy and tolerability of these two drugs, a randomized clinical trail with a larger sample size is needed.

\subsection{Other Pharmacological Preferences}

Benzodiazepines (such as clonazepam and diazepam), haloperidol, and sulpiride are also frequently prescribed drugs to reduce chorea in daily clinical practice $[10,11,25]$.

Although it is suggested that benzodiazepines have a beneficial effect on motor signs, no clinical trials have investigated this effect on chorea. Only two case reports showed some favorable effect of clonazepam (dosage up to $5.5 \mathrm{mg}$ per day) [88, 89], and among HD experts, clonazepam is only used as an adjunctive therapy [10].
Haloperidol and sulpiride are both classic first-generation antipsychotics drugs that were previously in favor for the treatment of choreiform movements in HD [90]. Three studies performed in the 1980s report a decrease of chorea in HD patients treated with haloperidol using doses ranging from 1.5 to $80 \mathrm{mg}$ per day [90-92]. Sulpiride was shown to have a positive effect on abnormal involuntary movements in one randomized, double-blind, crossover study [93]. Due to the high risk of adverse effects, such as tardive dyskinesia and drug induced-parkinsonism, and the introduction of newer second-generation antipsychotics, these drugs are now considered not to be beneficial to treat chorea in HD. Still, $24 \%$ of the respondents of the international group of HD experts preferred haloperidol as a first choice of antipsychotic drug [10]. In Europe, an assessment of medication use across HD patients showed that $6 \%$ of the registered patients received haloperidol and another $6 \%$ received sulpiride [11].

The efficacy of levetiracetam for reducing chorea has been investigated in two small open-label studies [94, 95]. In one study, 15 HD patients were treated with levetiracetam as an add-on therapy and showed a significant improvement on chorea scores after a 6-month treatment without reporting any adverse effects [94]. Another open-label study also showed a significant improvement on the UHDRS chorea score in nine HD patients [95]. However, somnolence contributed to a dropout rate of $33 \%$ and Parkinsonism was reported as an additional adverse effect.

\subsection{Potential New Treatment Options}

There are currently several ongoing or recently completed clinical trials in HD (http://www.clinicaltrials.gov [accessed 16 August 2016]). Active ongoing clinical trials investigating potential drugs to reduce motor symptoms in HD are summarized in Table 3.

Recently completed studies that showed no significant benefit on motor symptoms include latrepirdine (dimebon), ethyl-eicosapentaenoic acid, nabilone, mavoglurant (AFQ256), and Sativex ${ }^{\circledR}$ (a cannabinoid drug) [96-100]. Promising treatment options are deutetrabenazine and pridopidine, which are being developed to target motor symptoms in HD.

\subsubsection{Deutetrabenazine}

SD-809 or deutetrabenazine is a newly developed VMAT2 inhibitor that is structurally related to tetrabenazine in a deuterated form. Deuterium is a naturally occurring, nontoxic form of hydrogen and can create stronger bonds with carbon than with hydrogen [101]. The specific sites of deuterium placement in deutetrabenazine are thought to 
increase the half-life of active circulating metabolites compared to tetrabenazine without changing its target pharmacology.

Due to the lower peak plasma concentrations, it is suggested that deutetrabenazine can reduce the peak dose side effects that occur when treating with tetrabenazine [102]. However, it is not known what adverse effects might occur if a higher dosage of deutetrabenazine is needed for effective treatment.

Recently, the FIRST-HD study, a randomized, controlled trial was conducted by the HSG to evaluate the efficacy, safety, and tolerability of deutetrabenazine for the treatment of chorea in HD [103]. In total, 90 participants were enrolled to receive either deutetrabenazine $(n=45)$ or placebo $(n=45)$ for 12 weeks, including an 8-week titration phase and a 4-week maintenance phase followed by a 1-week washout. Patients gradually increased the dose weekly by $6 \mathrm{mg}$ per day, with a maximum dose of $48 \mathrm{mg}$ per day, or when a clinically significant serious adverse event occurred.

Deutetrabenazine significantly reduced chorea in patients with HD based on a reduction of 2.5 points on the total maximal chorea score of the UHDRS compared to placebo $(p<0.001)$. Deutetrabenazine also significantly improved overall motor function based on a reduction of 4.0 points on the total motor score of the UHDRS compared to placebo $(p=0.002)$. The safety profile of deutetrabenazine was similar to placebo. The most commonly reported adverse event in the deutetrabenazine group was somnolence, which generally resolved without reducing the dosage. Also, a weight increase of 0.7 on the body mass index (BMI) scale was reported for the deutetrabenazine group compared to placebo $(p=0.002)$. Subjectively, patients treated with deutetrabenazine reported more overall functional improvement then patients in the placebo group.

Long-term use of deutetrabenazine is currently being examined in an ongoing open-label safety study (the ARCHD study). This study aims to evaluate the safety, tolerability, and pharmacokinetics of deutetrabenazine in patients with HD switching from tetrabenazine to deutetrabenazine. Preliminary results of this study after 8 weeks of treatment with deutetrabenazine showed a significant improvement on the total chorea motor score in 37 patients with HD that switched overnight from three times daily tetrabenazine to twice daily deutetrabenazine [104].

Thus far, deutetrabenazine seems to be effective in treating chorea in HD with no significant adverse effects compared with placebo. Currently, the FDA has accepted the New Drug Application (NDA) for deutetrabenazine for the treatment of chorea and the Prescription Drug User Free Act (PDUFA) date is set for 3 April 2017.

\subsubsection{Pridopidine}

Pridopidine (formerly known as ACR-16) is a recently developed drug that belongs to a new class of pharmacological agents known as dopidines, which act as dopamine stabilizers. By binding to striatal dopamine $\mathrm{D}_{2}$ receptors, pridopidine can reverse and improve behavioral states by modulating hyperactivity or hypoactivity of the dopaminergic system, without having major effects on normal psychomotor function [105, 106].

Pridopidine is orally administered and has a rapid absorption, with peak plasma concentrations within $0.5-4 \mathrm{~h}$ and an elimination half-life between 10 and $14 \mathrm{~h}$, with elimination partly by urinary excretion and partly by hepatic metabolism [106].

Three randomized, placebo-controlled clinical studies have investigated the efficacy and safety of pridopidine in HD [107-109]. The primary outcome measure for all studies was change in the modified motor score (mMS), comprising 13 items from the UHDRS (the items chorea, dystonia, and ocular movements were excluded to reduce potential noise in the motor results), with a maximum score of 52 .

The first study examined the efficacy of $50 \mathrm{mg}$ pridopidine $(n=28)$ compared to placebo $(n=30)$ for 4 weeks [107]. In this study, patients treated with pridopidine showed improved modified motor scores after 4 weeks but this improvement of 2.9 units in the pridopidine group was not significantly different from the 0.9-unit improvement in the placebo group.

The HART (Huntington's Disease ACR16 Randomized Trial) study was conducted in 227 patients with HD as a dose-finding study $(20 \mathrm{mg}, 45 \mathrm{mg}$, and $90 \mathrm{mg}$ pridopidine daily) for 12 weeks [108]. Simultaneously with the HART study, the MermaiHD (Multinational European Multicenter ACR16 study in Huntington's Disease) study compared $45 \mathrm{mg}(n=148)$ and $90 \mathrm{mg}(n=145)$ pridopidine daily with placebo $(n=144)$ after 26 weeks treatment [109].

In both the HART and MermaiHD studies, there was a trend for a positive effect on the mMS for the 45 and $90 \mathrm{mg}$ pridopidine dosages, but this did not reach the pre-specified significance criteria [108, 109]. Still, significant improvements in the pridopidine group were found for the UHDRS total motor score in both studies. This was primarily driven by improvements on dystonia and eye movement scores.

Overall, pridopidine was well tolerated with an adverse event profile similar to placebo. Reported adverse effects include falls, fatigue, depression, agitation, nausea, diarrhea, and dizziness [107-109].

Although these three studies did not detect any significant results on their primary outcome measure (mMS), a marginal effect was seen in the total motor score for the highest dose range. Higher dosages of pridopidine (90, 135, 
Table 3 Ongoing clinical trials for treatment of chorea in Huntington's disease

\begin{tabular}{|c|c|c|c|c|c|}
\hline Study & Phase & Design & Study agent & Outcome measures & Trial length \\
\hline $\begin{array}{l}\text { ARC-HD } \\
\text { (NCT01897896) }\end{array}$ & III & $\begin{array}{l}\text { Multicenter, open-label, long- } \\
\text { term safety extension study } \\
\text { of FIRST-HD }\end{array}$ & $\begin{array}{l}\text { Deutetrabenazine } \\
6,9 \text {, or } \\
12 \mathrm{mg} / \text { day }\end{array}$ & $\begin{array}{l}\text { Incidence of adverse events, change from } \\
\text { baseline in clinical laboratory parameters, } \\
\text { vital signs and UHDRS }\end{array}$ & $\begin{array}{l}\text { Up to } \\
58 \text { weeks }\end{array}$ \\
\hline NCT02197130 & II & $\begin{array}{l}\text { Randomized, double-blind, } \\
\text { placebo-controlled efficacy } \\
\text { and safety study }\end{array}$ & $\begin{array}{l}\text { PF-02545920 } \\
5 \mathrm{mg} \text { and } \\
20 \mathrm{mg} / \text { day }\end{array}$ & $\begin{array}{l}\text { Change from baseline in UHDRS- TMS and } \\
\text { total maximum chorea score }\end{array}$ & 26 weeks \\
\hline $\begin{array}{l}\text { NEUROHD } \\
\text { (NCT00632645) }\end{array}$ & III & $\begin{array}{l}\text { Multicenter, randomized, } \\
\text { controlled comparison } \\
\text { study }\end{array}$ & $\begin{array}{l}\text { Olanzapine } \\
2.5-20 \mathrm{mg} / \text { day } \\
\text { Tetrabenazine } \\
25-200 \mathrm{mg} / \text { day } \\
\text { Tiapride } \\
300-800 \mathrm{mg} / \text { day }\end{array}$ & $\begin{array}{l}\text { Change in independence, motor, psychiatric } \\
\text { and cognitive scales, assessment of adverse } \\
\text { effects }\end{array}$ & 52 weeks \\
\hline $\begin{array}{l}\text { PRIDE-HD } \\
\text { (NCT02006472) }\end{array}$ & II b & $\begin{array}{l}\text { Multicenter, randomized, } \\
\text { double-blind, placebo- } \\
\text { controlled safety and } \\
\text { efficacy study }\end{array}$ & $\begin{array}{l}\text { Pridopidine } 45, \\
67.5,90, \\
112.5 \mathrm{mg} \text { twice } \\
\text { daily }\end{array}$ & $\begin{array}{l}\text { Change from baseline in UHDRS-TMS and } \\
\text { mPPT }\end{array}$ & $\begin{array}{l}26 \text { and } \\
52 \text { weeks }\end{array}$ \\
\hline $\begin{array}{l}\text { Open-Hart } \\
\text { (NCT01306929) }\end{array}$ & II & $\begin{array}{l}\text { North-American, long-term } \\
\text { open-label extension study } \\
\text { of PRIDE-HD }\end{array}$ & Pridopidine $45 \mathrm{mg}$ & $\begin{array}{l}\text { Number of adverse events, development of } \\
\text { UHDRS-TMS over time }\end{array}$ & $\begin{array}{l}\text { Up to } \\
2 \text { years }\end{array}$ \\
\hline $\begin{array}{l}\text { Open-Pride } \\
\text { (NCT02494778) }\end{array}$ & II & $\begin{array}{l}\text { Multicenter, open-label } \\
\text { safety, tolerability and } \\
\text { efficacy extension study of } \\
\text { PRIDE-HD }\end{array}$ & $\begin{array}{l}\text { Pridopidine } 45 \mathrm{mg} \\
\text { twice daily }\end{array}$ & $\begin{array}{l}\text { Percentage of participants with adverse events, } \\
\text { change in UHDRS-TMS over time }\end{array}$ & 2 years \\
\hline $\begin{array}{l}\text { Legato } \\
\text { (NCT02215616) }\end{array}$ & II & $\begin{array}{l}\text { Multicenter, randomized, } \\
\text { double-blind, placebo- } \\
\text { controlled efficacy and } \\
\text { safety study }\end{array}$ & $\begin{array}{l}\text { Laquinimod } 0.5 \text {, } \\
1.0 \text {, and } \\
1.5 \mathrm{mg} / \text { day }\end{array}$ & $\begin{array}{l}\text { Change from baseline in UHDRS-TMS, } \\
\text { percent change in caudate volume and HD- } \\
\text { CAB total score }\end{array}$ & 12 months \\
\hline $\begin{array}{l}\text { Trihep3 } \\
\text { (NCT02453061) }\end{array}$ & II & $\begin{array}{l}\text { Randomized, double-blind, } \\
\text { controlled study }\end{array}$ & $\begin{array}{l}\text { Triheptanoin oil } \\
1 \mathrm{~g} / \mathrm{kg} / \text { day }\end{array}$ & $\begin{array}{l}\text { Change in index of brain energy restoration } \\
\text { using 31-P MRS and change of caudate } \\
\text { atrophy rate using MRI. Change in motor } \\
\text { function }\end{array}$ & $\begin{array}{l}6 \text { and } \\
12 \text { months }\end{array}$ \\
\hline
\end{tabular}

Information on current ongoing clinical trials investigating the efficacy on chorea in patients with Huntington's disease obtained from http:// www.clinicaltrials.gov [accessed 16 August 2016]

$H D$ Huntington's disease, UHDRS-TMS Unified Huntington's Disease Rating Scale-Total Motor Score, $m P P T$ modified Physical Performance Test, 31-P MRS 31-Phosophorus Magnetic Resonance Spectroscopy, MRI magnetic resonance imaging, HD-CAB Huntington's Disease Cognitive Assessment Battery

180 , and $225 \mathrm{mg}$ daily) have been recently studied in the PRIDE-HD study, a large, multicenter, double-blind, dosefinding phase II trial, which will also assess the long-term safety in an open-label extension study [110, 111]. Preliminary results of this study were presented at the 9th European Huntington Disease Network Plenary Meeting in September 2016 and showed that an unexpectedly high placebo effect limited the ability to determine treatment effects of pridopidine on motor symptoms measured using the UHDRS-TMS. Thus, pridopidine failed to meet the primary endpoint in this trial, also in the group of patients taking lower dosages. In the early stage HD subpopulation, a slight improvement in the UHDRS-TMS was observed at specific dosages. Also, a potential improvement on disease progression was seen as measured with the Total Functional Capacity (TFC) score compared to placebo. Since the effect on the TFC score was an explorative endpoint, further evaluation of the results will need to determine its potential effect on disease progression and reducing chorea in patients with HD.

\section{Conclusions}

This review provides an overview of the current evidence and clinical experience on pharmacological options for the treatment of chorea in HD. HD is a disease with a heterogeneous combination of motor disturbances, psychiatric symptoms, and cognitive impairment. Thus, treatment options need to be carefully evaluated on an individual basis prior to initiating pharmacological treatment.

A longitudinal study showed that choreatic symptoms decrease over time and hypokinetic-rigid symptoms 
become more pronounced [112]. Therefore, annual followup visits in the outpatient clinic or by using the longitudinal observational REGISTRY and ENROLL-HD studies can be useful to assess if disease progression warrants a reduction in treatment dosage or a switch in prescribed drugs.

Despite the lack of evidence-based randomized, controlled studies, dopamine antagonists seem to have a beneficial effect on chorea in HD. Many clinicians use olanzapine, risperidone, or tiapride as a first choice of treatment, as they additionally have a positive effect on sleep dysfunction (due to the sedative effects), mood disturbances, and weight gain [113].

Tetrabenazine is the only drug for the treatment of chorea in HD that is approved by the FDA and the risk of developing a metabolic syndrome or tardive dyskinesia is lower than seen in antipsychotic drugs. In large randomized clinical trials, tetrabenazine proved to be beneficial in reducing chorea [39]. However, because of the increased risk of depression and suicidal behavior, the use of tetrabenazine can be limited. Hence, the recently developed deutetrabenazine forms an interesting pharmacological agent, as preliminary results show a beneficial effect on chorea with less adverse effects than seen when treating with tetrabenazine [103].

Overall, assessing the efficacy of drugs in HD patients is challenging, as most studies are underpowered, have a small treatment duration, use different (sometimes not validated) rating scales as outcome measures, and do not have a randomized, double-blind study design. Also, there is limited interest from pharmaceutical companies to conduct a trial for commonly used antipsychotic drugs that have no patent rights. Therefore it is meaningful to not only focus on evidence-based results but also on treatment guidelines developed by expert opinions [46].

The UHDRS is frequently used as a primary endpoint in clinical therapeutic trials, as this clinical rating scale is practical in assessing general motor impairment. Still, it might not be the most sensitive tool to detect small changes in the severity of choreiform movements, as the scale seems to be less sensitive in detecting mild clinical signs [3].

New innovative tools are currently used to measure chorea objectively, such as quantitative assessment of chorea with choreomotography, a noninvasive and easy applicable method that might be a valuable primary endpoint for future clinical trials [114].

More randomized, controlled trials and long-term evaluation on symptomatic treatment for chorea are currently ongoing and are needed to better assess the efficacy of potentially effective drugs. Also, future studies comparing different treatment options are interesting for analyzing between-drug efficacy and adverse effects.

\section{Compliance with Ethical Standards}

Funding None.

Conflict of interest EM Coppen has no conflicts of interest to declare. R. A. C. Roos received research grants from the CHDI Foundation, Gossweiler Foundation, and Teva Pharmaceutical Industries, Ltd.

Open Access This article is distributed under the terms of the Creative Commons Attribution-NonCommercial 4.0 International License (http://creativecommons.org/licenses/by-nc/4.0/), which permits any noncommercial use, distribution, and reproduction in any medium, provided you give appropriate credit to the original author(s) and the source, provide a link to the Creative Commons license, and indicate if changes were made.

\section{References}

1. Roos RAC. Huntington's disease: a clinical review. Orphanet J Rare Dis. 2010;5:40.

2. Mestre T, Ferreira J, Coelho MM, Rosa M, Sampaio C. Therapeutic interventions for symptomatic treatment in Huntington's disease. Cochrane Database Syst Rev. 2009;(3):CD006456. doi:10.1002/14651858.CD006456.pub2.

3. Jankovic J, Roos RAC. Chorea associated with Huntington's disease: to treat or not to treat? Mov Disord. 2014;29:1414-8.

4. The Huntington's Disease Collaborative Research Group. A novel gene containing a trinucleotide repeat that is expanded and unstable on Huntington's disease chromosomes. Cell. 1993;72: 971-83.

5. De la Monte S, Vonsattel J, Richardson E. Morphometric demonstration of atrophic changes in cerebral cortex, white matter and neostriatum in Huntington's disease. J Neuropathol Exp Neurol. 1988;47:516-25.

6. Vonsattel JP, Myers RH, Stevens TJ, Ferrante RJ, Bird ED, Richardson EP. Neuropathological classification of Huntington's disease. J Neuropathol Exp Neurol. 1985;44:559-77.

7. Reiner A, Albin RL, Anderson KD, D'Amato CJ, Penney JB, Young AB. Differential loss of striatal projection neurons in Huntington disease. Proc Natl Acad Sci USA. 1988;85:5733-7.

8. Vonsattel JP, DiFiglia M. Huntington disease. J Neuropathol Exp Neurol. 1998;57:369-84.

9. Frank S. Treatment of Huntington's disease. Neurotherapeutics. 2014;11:153-60.

10. Burgunder JM, Guttman M, Perlman S, Goodman N, van Kammen DP, Goodman L. An international survey-based algorithm for the pharmacologic treatment of chorea in Huntington's disease. PLoS Curr. 2011;3:RRN1260.

11. Priller J, Ecker D, Landwehrmeyer B, Craufurd D. A Europewide assessment of current medication choices in Huntington's disease. Mov Disord. 2008;23:1788.

12. Wojtecki L, Groiss S, Ferrea S, Elben S, Hartmann C, Dunnett $\mathrm{S}$, et al. A prospective pilot trial for pallidal deep brain stimulation in Huntington's disease. Front Neurol. 2015;6:1-11.

13. van Duijn E, Craufurd D, Hubers AAM, Giltay EJ, Bonelli R, Rickards $\mathrm{H}$, et al. Neuropsychiatric symptoms in a European Huntington's disease cohort (REGISTRY). J Neurol Neurosurg Psychiatry. 2014;85:1411-8.

14. Rosenblatt A, Kumar BV, Mo A, Welsh CS, Margolis RL, Ross CA. Age, CAG repeat length, and clinical progression in Huntington's disease. Mov Disord. 2012;27:272-6.

15. Paulsen JS, Long JD. Onset of Huntington's disease: can it be purely cognitive? Mov Disord. 2014;29:1342-50. 
16. Paulsen JS. Cognitive impairment in Huntington disease: diagnosis and treatment. Curr Neurol Neurosci Rep. 2011;11: 474-83.

17. Roos RAC. Clinical neurology. In: Bates G, Tabrizi S, Jones L, editors. Huntington's dis. 4th ed. Oxford: Oxford University Press; 2014. p. 25-35.

18. Albanese A, Bhatia K, Bressman SB, Delong MR, Fahn S, Fung VSC, et al. Phenomenology and classification of dystonia : a consensus update. Mov Disord. 2013;28:863-73.

19. Huntington Study Group. Unified Huntington's disease rating scale: reliability and consistency. Mov Disord. 1996;11:136-42.

20. Ross CA, Pantelyat A, Kogan J, Brandt J. Determinants of functional disability in Huntington's disease: role of cognitive and motor dysfunction. Mov Disord. 2014;29:1351-8.

21. Grimbergen YMA, Knol MJ, Bloem BR, Kremer BPH, Roos RAC, Munneke M. Falls and gait disturbances in Huntington's disease. Mov Disord. 2008;23:970-6.

22. Wheelock VL, Tempkin T, Marder K, Nance M, Myers RH, Zhao $\mathrm{H}$, et al. Predictors of nursing home placement in Huntington disease. Neurology. 2003;60:998-1001.

23. Ho AK, Gilbert AS, Mason SL, Goodman AO, Barker RA. Health-related quality of life in Huntington's disease: which factors matter most? Mov Disord. 2009;24:574-8.

24. Helder DI, Kaptein AA, van Kempen GMJ, van Houwelingen JC, Roos RAC. Impact of Huntington's disease on quality of life. Mov Disord. 2001;16:325-30.

25. Orth M, Handley O, Schwenke C, Dunnett S, Craufurd D, Ho A, et al. Observing Huntington's disease: the European Huntington's disease Network's REGISTRY. PLoS Curr. 2010;1:1-17.

26. Levine MS, Wang EA, Chen JY, Cepeda C, Andre VM. Altered neuronal circuitry. In: Bates G, Tabrizi SJ, Jones L, editors. Huntington's dis. 4th ed. Oxford: Oxford University Press; 2014. p. 218-40.

27. André VM, Cepeda C, Levine MS. Dopamine and glutamate in Huntington's disease: a balancing act. CNS Neurosci Ther. 2010;16:163-78.

28. Schwab LC, Garas SN, Drouin-Ouellet J, Mason SL, Stott SR, Barker RA. Dopamine and Huntington's disease. Expert Rev Neurother. 2015;15:445-58.

29. Beaulieu J-M, Gainetdinov RR. The physiology, signaling, and pharmacology of dopamine receptors. Pharmacol Rev. 2011;63:182-217.

30. Pagano G, Niccolini F, Politis M. Current status of PET imaging in Huntington's disease. Eur J Nucl Med Mol Imaging. 2016;43:1171-82.

31. Pavese N, Andrews TC, Brooks DJ, Ho AK, Rosser AE, Barker RA, et al. Progressive striatal and cortical dopamine receptor dysfunction in Huntington's disease: a PET study. Brain. 2003; 126:1127-35.

32. Ginovart N, Lundin A, Farde L, Halldin C, Bäckman L, Swahn $\mathrm{CG}$, et al. PET study of the pre- and post-synaptic dopaminergic markers for the neurodegenerative process in Huntington's disease. Brain. 1997;120:503-14.

33. Andrews TC, Weeks RA, Turjanski N, Gunn RN, Watkins LH, Sahakian B, et al. Huntington's disease progression. PET and clinical observations. Brain. 1999;122:2353-63.

34. Carroll JB, Bates GP, Steffan J, Saft C, Tabrizi SJ. Treating the whole body in Huntington' $\mathrm{s}$ disease. Lancet Neurol. 2015; 14:1135-42.

35. Chen JJ, Ondo WG, Dashtipour K, Swope DM. Tetrabenazine for the treatment of hyperkinetic movement disorders: a review of the literature. Clin Ther. 2012;34:1487-504 (Elsevier Inc.).

36. Scherman D, Jaudon P, Henry JP. Characterization of the monoamine carrier of chromaffin granule membrane by binding of $[2-3 \mathrm{H}]$ dihydrotetrabenazine. Proc Natl Acad Sci USA. 1983;80:584-8.
37. Guay DRP. Tetrabenazine, a monoamine-depleting drug used in the treatment of hyperkinetic movement disorders. Am J Geriatr Pharmacother. 2010;8:331-73 (Excerpta Medica Inc.).

38. Jankovic J, Clarence-smith K. Tetrabenazine for the treatment of chorea and other hyperkinetic movement disorders. Expert Rev Neurother. 2011;11:1509-23.

39. Huntington Study Group. Tetrabenazine as antichorea therapy in Huntington disease: a randomized controlled trial. Neurology. 2006;66:366-72.

40. Frank S. Tetrabenazine as anti-chorea therapy in Huntington disease: an open-label continuation study. Huntington Study Group/TETRA-HD Investigators. BMC Neurol. 2009;9:62.

41. Jankovic J, Beach J. Long-term effects of tetrabenazine in hyperkinetic movement disorders. Neurology. 1997;48:358-62.

42. Ondo WG, Tintner R, Thomas M, Jankovic J. Tetrabenazine treatment for Huntington's disease-associated chorea. Clin Neuropharmacol. 2002;25:300-2.

43. Kenney C, Hunter C, Davidson A, Jankovic J. Short-term effects of tetrabenazine on chorea associated with Huntington's disease. Mov Disord. 2007;22:10-3.

44. Fasano A, Cadeddu F, Guidubaldi A, Piano C, Soleti F, Zinzi P, et al. The long-term effect of tetrabenazine in the management of Huntington disease. Clin Neuropharmacol. 2008;31:313-8.

45. Burgunder J-M. Recent advances in the management of choreas. Ther Adv Neurol Disord. 2013;6:117-27.

46. Reilmann R. Pharmacological treatment of chorea in Huntington's disease-good clinical practice versus evidence-based guideline. Mov Disord. 2013;28:1030-3.

47. Venuto CS, Mcgarry A, Ma Q, Kieburtz K. Pharmacologic approaches to the treatment of Huntington's disease. Mov Disord. 2012;27:31-41.

48. Frank S, Jankovic J. Advances in the pharmacological management of Huntingtons disease. Drugs. 2010;70:561-71.

49. Armstrong MJ, Miyasaki JM. Evidence-based guideline: Pharmacologic treatment of chorea in Huntington disease: Report of the Guideline Development Subcommittee of the American Academy of Neurology. Neurology. 2012;79:597-603.

50. Dose M, Lange HW. The benzamide tiapride: treatment of extrapyramidal motor and other clinical syndromes. Pharmacopsychiatry. 2000;33:19-27.

51. Roos RA, Buruma OJ, Bruyn GW, Kemp B, van der Velde E. Tiapride in the treatment of Huntington's chorea. Acta Neurol Scand. 1982;65:45-50.

52. Deroover J, Baro F, Bourguignon RP, Smets P. Tiapride versus placebo: a double-blind comparative study in the management of Huntington's chorea. Curr Med Res Opin. 1984;9:329-38.

53. Iqbal MM, Rahman A, Husain Z, Mahmud SZ, Ryan WG, Feldman JM. Clozapine: a clinical review of adverse effects and management. Ann Clin Psychiatry. 2003;15:33-48.

54. Caine ED, Polinsky RJ, Kartzinel R, Ebert MH. The trial use of clozapine for abnormal involuntary movement disorders. Am J Psychiatry. 1979;136:317-20.

55. Bonuccelli U, Ceravolo R, Maremmani C, Nuti A, Rossi G, Muratorio A. Clozapine in Huntington's chorea. Neurology. 1994:44:821-3.

56. van Vugt JP, Siesling S, Vergeer M, van der Velde EA, Roos RA. Clozapine versus placebo in Huntington's disease: a double blind randomised comparative study. J Neurol Neurosurg Psychiatry. 1997;63:35-9.

57. Bogelman G, Hirschmann S, Modai I. Olanzapine and Huntington's disease. J Clin Psychopharmacol. 2001;21:245.

58. Mauri MC, Paletta S, Maffini M, Colasanti A, Dragogna F, Di Pace C, et al. Clinical pharmacology of atypical antipsychotics: an update. EXCLI J. 2014; 13:1163-91.

59. Videnovic A. Treatment of huntington disease. Curr Treat Options Neurol. 2013;15:424-38. 
60. Dipple H. The use of olanzapine for movement disorder in Huntington's disease: a first case report. J Neurol Neurosurg Psychiatry. 1999;67:123-4.

61. Squitieri F, Cannella M, Piorcellini A, Brusa L, Simonelli M, Ruggieri S. Short-term effects of olanzapine in Huntington disease. Neuropsychiatry Neuropsychol Behav Neurol. 2001;14:69-72.

62. Bonelli R, Mahnert F, Niederwieser G. Olanzapine for Huntington's disease: an open label study. Clin Neuropharmacol. 2002;25:263-5.

63. Paleacu D, Anca M, Giladi N. Olanzapine in Huntington's disease. Acta Neurol Scand. 2002;105:441-4.

64. Brown CS, Markowitz JS, Moore TR, Parker NG. Atypical antipsychotics: part II. Adverse effects, drug interactions, and costs. Ann Pharmacother. 1999;33:210-7.

65. Komossa K, Rummel-Kluge C, Schwarz S, Schmid F, Hunger H, Kissling W, Leucht S. Risperidone versus other atypical antipsychotics for schizophrenia. Cochrane Database Syst Rev. 2011;(1):CD006626.

66. Reveley MA, Dursun SM, Andrews H. A comparative trial use of sulpiride and risperidone in Huntington's disease: a pilot study. J Psychopharmacol. 1996;10:162-5.

67. Dallocchio C, Buffa C, Tinelli C, Mazzarello P. Effectiveness of risperidone in Huntington Chorea patients. J Clin Psychopharmacol. 1999;19:101-3.

68. Erdemoglu AK, Boratov C. Risperidone in chorea and psychosis of Huntington's disease. Eur J Neurol. 2002;9:182-3.

69. Cankurtaran ES, Ozalp E, Soygur H, Cakir A. Clinical experience with risperidone and memantine in the treatment of Huntington's disease. J Natl Med Assoc. 2006;98:1353-5.

70. Duff K, Beglinger LJ, O'Rourke ME, Nopoulos P, Paulson HL, Paulsen JS. Risperidone and the treatment of psychiatric, motor, and cognitive symptoms in Huntington's disease. Ann Clin Psychiatry. 2008;20:1-3.

71. Seitz D, Millson R. Quetiapine in the management of psychosis secondary to Huntington's disease: a case report. Can J Psychiatry. 2004;49:413.

72. Alpay M, Koroshetz WJ. Quetiapine in the treatment of behavioral disturbances in patients with Huntington's disease. Psychosomatics. 2006;47:70-2.

73. Bonelli RM, Niederwieser G. Quetiapine in Huntington's disease: a first case report. J Neurol. 2002;249:1114-5.

74. Goetz CG, Koller WC, Poewe W, Rascol O, Sampaio C, Brin $\mathrm{MF}$, et al. Amantadine and other antiglutamate agents. Mov Disord. 2002;17:S13-22.

75. Verhagen L, Morris M, Farmer C, Gillespie M, Mosby K, Wuu $\mathrm{J}$, et al. Huntington's disease: a randomized, controlled trial using the NMDA-antagonist amantadine. Neurology. 2002;59:694-9.

76. O'Suilleabhain P, Dewey RB. A randomized trial of amantadine in Huntington disease. Arch Neurol. 2003;60:996-8.

77. Lucetti C, Gambaccini G, Bernardini S, Dell'Agnello G, Petrozzi L, Rossi G, et al. Amantadine in Huntington's disease: open-label video-blinded study. Neurol Sci. 2002;23(Suppl 2):S83-4.

78. Wokke J. Riluzole. Lancet. 1996;348:795-9.

79. Rosas HD, Koroshetz WJ, Jenkins BG, Chen YI, Hayden DL, Beal MF, et al. Riluzole therapy in Huntington's disease (HD). Mov Disord. 1999;14:326-30.

80. Seppi K, Mueller J, Bodner T, Brandauer E, Benke T, WeirichSchwaiger H, et al. Riluzole in Huntington's disease (HD): an open label study with one year follow up. J Neurol. 2001;248:866-9.

81. Huntington Study Group. Dosage effects of riluzole in Huntington's disease: a multicenter placebo-controlled study. Neurology. 2003;61:1551-6.
82. Landwehrmeyer GB, Dubois B, De Yebenes JG, Kremer B, Gaus W, Kraus PH, et al. Riluzole in Huntington's disease: a 3-year, randomized controlled study. Ann Neurol. 2007;62:262-72.

83. Miller R, Mitchell J, Moore D. Riluzole for amyotrophic lateral sclerosis (ALS)/motor neuron disease (MND). Cochrane Database Syst Rev. 2012;(3):CD001447. doi:10.1002/14651858. CD001447.pub3.

84. Shirley M, Perry CM. Aripiprazole (Abilify maintena): a review of its use as maintenance treatment for adult patients with schizophrenia. Drugs. 2014;74:1097-110.

85. Ciammola A, Sassone J, Colciago C, Mencacci NE, Poletti B, Ciarmiello A, et al. Aripiprazole in the treatment of Huntington's disease: a case series. Neuropsychiatr Dis Treat. 2009;5:1-4.

86. Brusa L, Orlacchio A, Moschella V, Iani C, Bernardi G, Mercuri NB. Treatment of the symptoms of Huntington's disease: preliminary results comparing aripiprazole and tetrabenazine. Mov Disord. 2009;24:126-9.

87. Pena MS, Yaltho TC, Jankovic J. Tardive dyskinesia and other movement disorders secondary to aripiprazole. Mov Disord. 2011;26:147-52.

88. Peiris J, Boralessa $\mathrm{H}$, Lionel N. Clonazepam in the treatment of choreiform activity. Med J Aust. 1976;1:225-7.

89. Stewart J. Treatment of Huntington's disease with clonazepam. South Med J. 1988;81:102.

90. Koller WC, Trimble J. The gait abnormality of Huntington's disease. Neurology. 1985;35:1450-4.

91. Girotti F, Carella F, Scigliano G, Grassi MP, Soliveri P, Giovannini $\mathrm{P}$, et al. Effect of neuroleptic treatment on involuntary movements and motor performances in Huntington's disease. J Neurol Neurosurg Psychiatry. 1984;47:848-52.

92. Barr AN, Fischer JH, Koller WC, Spunt AL, Singhal A. Serum haloperidol concentration and choreiform movements in Huntington's disease. Neurology. 1988;38:84-8.

93. Quinn N, Marsden CD. A double blind trial of sulpiride in Huntington's disease and tardive dyskinesia. J Neurol Neurosurg Psychiatry. 1984;47:844-7.

94. de Tommaso M, di Fruscolo O, Sciruicchio V, Specchio N, Cormio C, De Caro MF, et al. Efficacy of levetiracetam in Huntington disease. Clin Neuropharmacol. 2005;28:280-4.

95. Zesiewicz TA. Open-label pilot study of levetiracetam (Keppra) for the treatment of chorea in Huntington's disease. Mov Disord. 2006;21:1998-2001.

96. Kieburtz K, McDermott MP, Voss TS, Corey-Bloom J, Deuel LM, Dorsey ER, et al. A randomized, placebo-controlled trial of latrepirdine in Huntington disease. Arch Neurol. 2010;67: 154-60.

97. Huntington Study Group. Randomized controlled trial of ethyleicosapentaenoic acid in Huntington disease: the TREND-HD study. Arch Neurol. 2008;65:1582-9.

98. Curtis A, Mitchell I, Patel S, Ives N, Rickards H. A pilot study using nabilone for symptomatic treatment in Huntington's disease. Mov Disord. 2009;24:2254-9.

99. Reilmann R, Rouzade-Dominguez M, Saft C, Sussmuth S, Priller J, Rosser A, et al. A randomized, placebo-controlled trial of AFQ056 for the treatment of chorea in Huntington's disease. Mov Disord. 2015;30:427-31.

100. Lopez-Sendon Moreno J, Caldentey J, Cubillo P, Ruiz Romero C, Ribas G, Arias M, et al. A double-blind, randomized, crossover, placebo-controlled, pilot trial with Sativex in Huntington's disease. J Neurol. 2016;263:1390-400.

101. Stamler D, Bradbury M, Brown F. The pharmacokinetics and safety of deuterated-tetrabenazine. Neurology. 2013;80: P07.210.

102. Claassen D, Carroll B, de Boer L, Wu E, Ayyagari R, Gandhi S, et al. Indirect comparison of tolerability of deutetrabenazine and 
tetrabenazine in the First-HD and Tetra-HD trials. Germany: Int Congr Park Dis Mov Disord Berlin; 2016.

103. Frank S, Testa CM, Stamler D, Kayson E, Davis C, Edmondson $\mathrm{MC}$, et al. Effect of deutetrabenazine on chorea among patients with Huntington disease: a randomized clinical trial. JAMA. 2016;316:40-50.

104. Sung V, Stamler D, Claassen D. Alternatives for reducing chorea in Huntington disease, a long-term trial (ARC-HD): updated week 8 results for the switch cohort [abstract]. Mov Disord. 2016;31.

105. Dyhring T, Nielsen E, Sonesson C, Pettersson F, Karlsson J, Svensson $\mathrm{P}$, et al. The dopaminergic stabilizers pridopidine (ACR16) and (-)-OSU6162 display dopamine D2 receptor antagonism and fast receptor dissociation properties. Eur J Pharmacol. 2010;628:19-26.

106. Ponten H, Kullingsjö J, Lagerkvist S, Martin P, Pettersson F, Sonesson $\mathrm{C}$, et al. In vivo pharmacology of the dopaminergic stabilizer pridopidine. Eur J Pharmacol. 2010;644:88-95.

107. Lundin A, Dietrichs E, Haghighi S, Göller M-L, Heiberg A, Loutfi G, et al. Efficacy and safety of the dopaminergic stabilizer pridopidine (ACR16) in patients with Huntington's disease. Clin Neuropharmacol. 2010;33:260-4.

108. Huntington Study Group HART Investigators. A randomized, double-blind, placebo-controlled trial of pridopidine in Huntington's disease. Mov Disord. 2013;28:1407-15.
109. De Yebenes JG, Landwehrmeyer B, Squitieri F, Reilmann R, Rosser A, Barker RA, et al. Pridopidine for the treatment of motor function in patients with Huntington's disease (MermaiHD): a phase 3, randomised, double-blind, placebo-controlled trial. Lancet Neurol. 2011;10:1049-57.

110. Shannon KM. Pridopidine for the treatment of Huntington's disease. Expert Opin Investig Drugs. 2016;25:485-92.

111. Squitieri F, de Yebenes JG. Profile of pridopidine and its potential in the treatment of Huntington disease: the evidence to date. Drug Des Devel Ther. 2015;9:5827-33.

112. Jacobs M, Hart EP, van Zwet EW, Bentivoglio AR, Burgunder JM, Craufurd D, et al. Progression of motor subtypes in Huntington's disease: a 6-year follow-up study. J Neurol. 2016;263:2080-5.

113. Mason SL, Barker RA. Advancing pharmacotherapy for treating Huntington's disease: a review of the existing literature. Expert Opin Pharmacother. 2016;17:41-52.

114. Reilmann R, Bohlen S, Kirsten F, Ringelstein EB, Lange HW. Assessment of involuntary choreatic movements in Huntington's disease-toward objective and quantitative measures. Mov Disord. 2011;26:2267-73. 